\title{
Learning styles towards mathematics achievements among higher education students
}

\author{
Sabri Ahmad*, Shuhaili Safee, Wan Mohamad Asyraf Bin Wan Afthanorhan \\ Department of Mathematics, Faculty of Science and Technology,Universiti Malaysia Terengganu, \\ 21030 Kuala Terengganu, Malaysia \\ *Corresponding author E-mail: sba@umt.edu.my
}

Copyright $\odot 2014$ Sabri Ahmad et al. This is an open access article distributed under the Creative Commons Attribution License, which permits unrestricted use, distribution, and reproduction in any medium, provided the original work is properly cited.

\begin{abstract}
Students all have unique learning styles and preferences. Some may like group instruction while others may enjoy individualized instruction. Some learners are more independent than other learners. The aim of the present study was to identify the learning styles towards mathematic achievements among higher education students. One hundred and fiftythree first year students in a mathematic course participated in the study. Grasha-Riehmann Learning Style Scale was used to determine students' learning styles. Grasha-Riehmann Learning Style Scale consists of six learning style (independent, dependent, avoidant, and participant, collaborative and competitive). By used cluster analysis, 4 cluster/groups are obtained. As cluster 1 is identified as collaborative and competitive, cluster 2 is collaborative, dependent and participant, cluster 3 competitive and cluster 4 is collaborative. Results based on ANOVA test shown that, there was no significant among students with different learning styles with respect to mathematic achievement.
\end{abstract}

Keywords: Cluster Analysis, Anova, Grasha-Riehmann Learning Style.

\section{Introduction}

Learning styles are various approaches or ways of learning. They involve educating methods, particular to an individual, which are presumed to allow that individual to learn best. A benchmark definition of 'learning styles' is 'characteristic cognitive, effective, and psychosocial behaviors that serve as relatively stable indicators of how learners perceive, interact with, and respond to the learning environment. Learning style is considered as the major influenced on the success of education among students and educators. This particular case study has been proposed by Grasha [4, 9] to determine the type of learning style provided through of an observation respectively. As we can see the system and management that implement for various countries is seem distinct to create an intellectual of students thereby can provide an immense impact on development of country. Thus, each country provides numerous skills to improve the quality and competitive of students towards their education and academics. In doing so, they began to race each other to prove their ability to compete at the top of education level through the achievement of students in examination skills. Based on students' performance in examinations held in each country, the results show the gulf between the countries has achieved a high level with the bottom. This is enough to prove that someone learning style or education instilled in each country is very different and certainly influence on student achievement.

Of address the issue of the capabilities of learning style for students, this paper intends to apply the cluster analysis that should be appropriate to carry out the subsequent analysis proposed. The potency of technique is managed to determine the type of learning style accordance of previous empirical research and of course the variables selected ought to be limited depends on the scenario solely. In the nature of social science, cluster analysis is capable to ascertain the scholar nowadays to classify the category of particular case study. As aforementioned, the scholars possibly will to accrue the specified indicators through the shift estimators in a same component particular. Specifically, all the indicators which having the same aim will be permuting in a one specified style. Thus, the scholars competent to identify the type of learning style aside determine the vital statistics of the case study. In addition, the capabilities of cluster analysis are not only prone to observed heterogeneity variables solely in while the scholar managed to create a comparison between 
groups in a multivariate analysis. Indeed, the other fit analysis has been widely spread apply throughout the world pertaining to multi-group analysis (modeling moderator in structural equation modeling), unfortunately, this mention analysis also success to equip the needs of any researchers or scholars if they know how draw the conclusion and contribution of the case study. Consequently, this research paper present that behavior analysis to let the readers enjoyed the particular study. Besides, the outcome appear through the analysis is also plausible.

\section{Objective of the study}

The objectives of this study are:

- $\quad$ To identify the type of learning style.

- $\quad$ To identify the type of learning style between male and female students.

- To investigate whether there are significance difference between learning style and mathematics achievements.

\section{Literature review}

According to Grasha defines learning style as child's preferences in thinking and interaction with other children in different classroom environments and experiences [8]. Grasha and Riechmann separated students into six groups: the ones who learn on their own (independent), the ones who are dependent to their teacher in learning (dependent), the ones who cooperate with others (collaborative), the one who compete with others (competitive), the ones who take part in activities (contributive), and the ones who are shy and uninterested in learning (avoidant) [16]. Thus, all of the six learning style will be implement in this work paper to classify the respondents behavior towards target population selected whereby multivariate analysis namely cluster analysis is the best way to accomplish the objective of the study.

For gender surely have two types of groups namely men and women and of course they are different but do these differences extend to learning styles? Although several researchers and scholars have ongoing to compile a database to clearly identify the female learning experience, there is not enough data yet too definitively answer questions comparing women's and men's learning styles. A report from the National Institutes of Health (NIH) found that gender differences in personality were remarkably robust across all cultures studied spread throughout the world [17]. Contrary to predictions from the social role model, gender differences were most pronounced in European and American cultures in which traditional sex roles are minimized," the authors concluded. Consequently, the author interest to address these issues in order to improve the recreation of the endeavor scholars to put on the particular analysis aside bear out the prior objective.

Learning is a lifelong process and is a continuous and never ending one. Teacher/lecture must assess individual learning style preferences and then adapt their delivery technique to improve the pace of learning according to learning styles of their students. Learning styles can help students learning more easily and effectively [12]. This is because when students understand their strength and weaknesses, they can learn with greater motivation. The level of learning achieved by a learner is one of the most important factors which indicate the success of a learning environment. Several studies have shown that academic performance of students is related to their learning styles [13]. Irrespective of the instrument used many studies have shown that learning styles plays an important role in the academic performance of students. The accommodation of students learning styles in the learning environment have resulted in improved test scores while a mismatch in learning characteristics and learning environment resulted in poor students' achievement. [1, $6,10]$. For that reasons, learning style also has been enjoyed among researchers in the whole country including Malaysia. Specifically, most of community begin realized the significant of learning style possible give an impact of education level perspectives. Thus, the introduction to PISA and TIMSS is appropriate enough to compare the level of apprentices towards the killer subjects such as mathematics and science.

This is probably accurate as an account of the traditional core of the concept, of learning styles. However, the term has always been used in a wide variety of ways to describe differences in the way people learn. Several other studies found that the existence of a definite relationship between specific aspects of learning styles and measured learning outcomes in terms of academic achievement. Learning style also plays a role in classroom performance. Thus, conclusion from different studies was that as scores in learning styles moves up the scale from dependent to independent so does academic achievement, which are indicators to academic success. [2, 5, 11, 14, 15]. In particular, the performance of achievement among students is influenced of learning style and that is why cluster analysis is applied to the case study.

\section{The research methodology}

\subsection{The target population of the study}

The population of the study is defined as mathematics students at higher education institution chosen whereby in Kuala Terengganu. In particular, the students from other field do not allowed answering the questionnaire provided. 


\subsection{The sampling method and data collection procedure}

The sampling technique used is the Random Sampling Technique. In this sampling technique, every individual has an equal opportunity for selection. The method that been used is as mechanical as picking strips of paper with names of students first year written on it from a hat while the data collector is blindfolded to do the random selection. 153 respondent from first year students participated in the study. Of the 153 respondent, 122 were female and 31 were male.

\subsection{The measuring instrument in the study}

The instrument used for this study is questionnaire. Questionnaires are used based on Grasha Riechmann Student Learning Style Scales [8], but the questionnaire has been modified from learning style to mathematics learning styles. The questionnaire contains 90 items that are tested using Likert scale which is Strongly Disagree, Disagree, Not Sure, Agree and Strongly Agree. Several questions related to demographics such as gender, occupation of parent, the last high school, qualifying for university and mathematical results in the previous examination. The latest result for mathematics achievements was acquires from lecturers of mathematics based on matrix number of respondents.

\subsection{Scope and limitation}

Scope: The scope of the study is only limited to the mathematics students at higher education institution whereby in mathematics and statistics students

Limitations: The results might only be generalized to the above population. In the other words, the findings might be different if the scope is increase to include more categories might pose different characteristics. Methodologically, the study only measures the learning styles of respondents for each item on a questionnaire in which provided based on empirical research.

\subsection{Cluster analysis}

Cluster analysis is a collection of statistical methods, which identifies groups of samples that behave similarly or show similar characteristics. The simplest mechanism is to partition the samples using measurements that capture similarity or distance between samples. In this way, clusters and groups are interchangeable words. Typically in clustering methods, all the samples with in a cluster are considered to be equally belonging to the cluster (as against belonging with certain probability). This multivariate analysis has been enjoyed popularly among scholars and researchers nowadays to figure out the type of learning style for each mathematics students in higher education institution grounded by Grasha Riehmann [4, 9]. In doing so, some of the researcher prone to find out their analysis with the graphic modeling since the application using SPSS may tedious and dissatisfied. Consequently, the Response Based Segmentation Partial Least Square Structural Equation Modeling (REBUS-PLS) is proposed to ignite the essence of scholars to apply this procedure. However, this work paper tend to use the SPSS to identify the classification of each individual students aside this package has been spread throughout the world and ease for the beginner and intermediate scholars. In order to assign students to the group (cluster), first students' mean scores for each group of learning styles were computed. In this study, there are six groups of learning styles. From these six groups, the cluster is formed based on Grasha Riehmann scale from low, mediate and high of learning styles [4, 9].

Table 1: Scale for Grasha Riehmann Students Learning Styles

$\begin{array}{ccc}\text { Low } & \text { Moderate } & \text { High } \\ {[1.0-2.7]} & {[2.8-3.8]} & {[3.9-5.0]} \\ {[1.0-1.8]} & {[1.9-3.1]} & {[3.2-5.0]} \\ {[1.0-2.7]} & {[2.8-3.4]} & {[3.5-5.0]} \\ {[1.0-2.9]} & {[3.0-4.0]} & {[4.1-5.0]} \\ {[1.0-1.7]} & {[1.8-2.8]} & {[2.9-5.0]} \\ {[1.0-3.0]} & {[3.1-4.1]} & {[4.2-5.0]}\end{array}$

The groups/cluster with high mean scores was clustered based on Grasha's categories [7]. Mean for each the learning style type (independent, avoidant, collaborative, dependent, competitive and participant) are compute based questionnaire. The items containing in questionnaire put randomly to stay away from bias result. The bias result tends to provide wrong conclusion of the case study and of course our whole contribution will be meaningless. For an example, for section A there are 90 questions. Mean for each learning style types are compute based on the scale from 1 to 5 as below:

Independent $=$ Mean $(\mathrm{A} 1+\mathrm{A} 7+\mathrm{A} 13+\mathrm{A} 19+\mathrm{A} 25+\mathrm{A} 31+\mathrm{A} 37+\mathrm{A} 43+\mathrm{A} 49+\mathrm{A} 55+\mathrm{A} 61+\mathrm{A} 67+\mathrm{A} 73+\mathrm{A} 79+$ A85).

Avoidant $=$ Mean $(\mathrm{A} 2+\mathrm{A} 8+\mathrm{A} 14+\mathrm{A} 20+\mathrm{A} 26+\mathrm{A} 32+\mathrm{A} 38+\mathrm{A} 44+\mathrm{A} 50+\mathrm{A} 56+\mathrm{A} 62+\mathrm{A} 68+\mathrm{A} 74+\mathrm{A} 80+\mathrm{A} 86)$ 
Collaborative $=$ Mean $(\mathrm{A} 3+\mathrm{A} 9+\mathrm{A} 15+\mathrm{A} 21+\mathrm{A} 27+\mathrm{A} 33+\mathrm{A} 39+\mathrm{A} 45+\mathrm{A} 51+\mathrm{A} 57+\mathrm{A} 63+\mathrm{A} 69+\mathrm{A} 75+\mathrm{A} 81+$ A87).

Dependent $=$ Mean $(\mathrm{A} 4+\mathrm{A} 10+\mathrm{A} 16+\mathrm{A} 22+\mathrm{A} 28+\mathrm{A} 34+\mathrm{A} 40+\mathrm{A} 46+\mathrm{A} 52+\mathrm{A} 58+\mathrm{A} 64+\mathrm{A} 70+\mathrm{A} 76+\mathrm{A} 82+$ A88).

Competitive $=$ Mean $(\mathrm{A} 5+\mathrm{A} 11+\mathrm{A} 17+\mathrm{A} 23+\mathrm{A} 29+\mathrm{A} 35+\mathrm{A} 41+\mathrm{A} 47+\mathrm{A} 53+\mathrm{A} 59+\mathrm{A} 65+\mathrm{A} 71+\mathrm{A} 77+\mathrm{A} 83+$ A89).

Participant $=$ Mean $(\mathrm{A} 6+\mathrm{A} 12+\mathrm{A} 18+\mathrm{A} 24+\mathrm{A} 30+\mathrm{A} 36+\mathrm{A} 42+\mathrm{A} 48+\mathrm{A} 54+\mathrm{A} 60+\mathrm{A} 66+\mathrm{A} 72+\mathrm{A} 78+\mathrm{A} 84+$ A90).

$*(\mathrm{~A}=$ question number from section $\mathrm{A})$. Example:

A1 = I prefer to work by myself on assignments in my courses (independent)

$\mathrm{A} 2$ = I would prefer that teachers ignore me in class (avoidant)

A3 = I enjoy hearing what other students think about issues raised in class (Collaborative)

A4 = I like it whenever teachers clearly state what is required and expected (dependent)

A5 = to do well, it is necessary to compete with other students for the teacher's attention (competitive)

A6 = I try to participate as much as I can in all aspects of a course (participant)

Once the scholars managed to compute the selective items according to the same cluster, the compute mean of selective items appear on the data sets of SPSS. In order to provide a better understanding for the procedures or cluster analysis, several steps established:

1) Click on compute mean. Rename the target variable according on your own interest. Make sure choose on the statistical at the Function Group and press mean of the function and special variable

2) Insert on respective indicators (items) into Numeric Expression. Make sure every time indicator import, put "comma" (e.g.: MEAN(A1, A7, A13,...) and close bracket as the end compute

3) Click "Ok"

Once the results appear on the data sets, the value obtained should be decimal places since the compute of mean. Afterwards, use the procedure of Data Transformation to recoding into the same variable. Recoding into different variable also can be conducted but that will be quite messy to keep the subsequent analysis.

1) Click on Transform and choose "Recode into same Variable"

2) Insert the new name of target variable into numeric variables

3) Click on Old and New values

4) At previous page, Grasha established the scale for each cluster. Thus, we will implement the scale on this procedure

5) Focus on Independent cluster for Low level [1.0-2.7], Mediates level [2.8-3.8], and High Level [3.9-5.0], and recode the value. Any value falls within range for each level should be Type 1 for low, Type 2 for mediate and Type 3 for high.

6) Then, click "Continue"

Once the result of the compute mean in data sets will totally converted, the scholars should rename the values in variable view. Then, we can address on the next analysis namely Analysis of Variance (ANOVA).

\subsection{One-way anova}

Analysis of Variance (ANOVA) is a useful statistical technique that is very widely and broadening used in business research, whether in marketing, human resource management, operation, finance and social science. ANOVA permits us to handle the data from experiments that have designs involving more two conditions. In the t-test we compared the means of two sets (either from two groups of participants- an independent t-test or from repeated measures design involving more than two conditions- a paired t-test). ANOVA will tell us whether the scores significantly vary across those conditions. But, it will not tell us whether condition 1 is significantly different from condition 3 , or whether condition 1 is significantly different from condition 2 . Such as comparison of specific means require some additional statistical procedures which we will cover in this research paper. This application is used to test the significant between the learning styles towards mathematics achievements. In order to accomplish the objective research, this paper intends to use this application for that purpose. This application can be performed in SPSS on the subsequent analysis once encountered the cluster analysis.

\section{Data analysis and result}

The data obtained from Grasha-Riechmann learning style scale were analyzed using SPSS (Statistical Package for Social Sciences) program. This case study present the analysis for threefold which is to determine the type of learning style for total population, male and female. Thus, the first part is directly on total population and the findings suggest the total population have four clusters with different learning style as presented in Table 5. Once we keep this substantive analysis, each group will bring different number of cluster. 
Table 2: Scale for Type of Cluster in Learning Style

\begin{tabular}{|c|c|c|c|}
\hline \multirow{2}{*}{ Cluster } & \multicolumn{3}{|c|}{ Scale } \\
\hline & Low & Mediate & High \\
\hline 1 & & Independent, Avoidant, Dependent, participant & Collaborative, competitive \\
\hline 2 & & Independent, Avoidant & $\begin{array}{l}\text { Collaborative, Dependent, Competitive, } \\
\text { Participant }\end{array}$ \\
\hline 3 & & $\begin{array}{l}\text { Independent, Avoidant, Collaborative, } \\
\text { Dependent, Participant }\end{array}$ & Competitive \\
\hline 4 & Independent & Avoidant, Dependent, Competitive, Participant & Collaborative \\
\hline
\end{tabular}

Based on Table 2 above, learning style for cluster 1 are highly in collaborative and competitive styles while independent, avoidant, dependent and participant styles are in moderate. Learning styles for cluster 2 are highly in collaborative, competitive, dependent and collaborative styles. Learning styles for cluster 3 are highly in competitive while moderate in independent, avoidant, collaborative, dependent and participant style. Lastly, learning styles for cluster 4 are highly collaborative, moderate in dependent, participant, avoidant and competitive while low in independent styles. On the use of high level for each cluster, Cluster 1 is identified as collaborative and competitive, cluster 2 is collaborative, dependent and participant while cluster 3 competitive. Lastly, cluster 4 is collaborative.

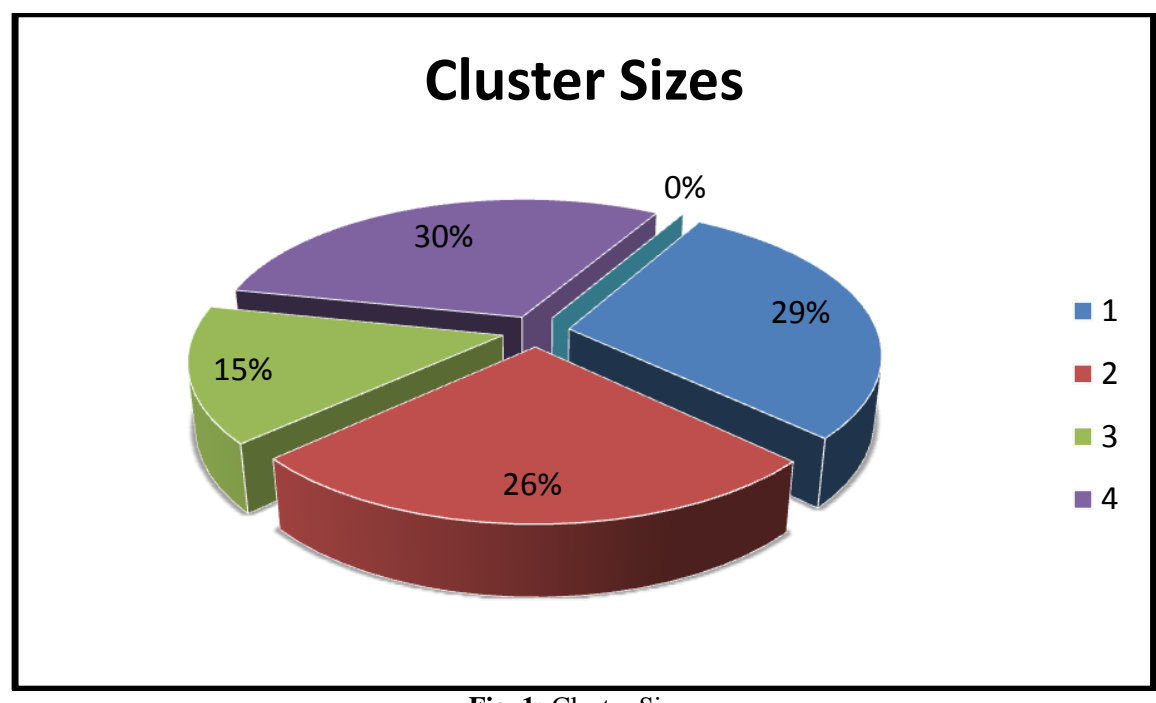

Fig. 1: Cluster Sizes

Figure 1 shows the frequency of each cluster. Hovering over a slice in the pie chart reveals the number of records assigned to the cluster. $29 \%$ (44) of the records were assigned to the first cluster, $26 \%$ (40) to the second, $15 \%$ (23) to the third and $30 \%$ (46) to the fourth cluster. Now, the gender group will be tested on the subsequent analysis through particular analysis. Table 6 present the outcome for male group which have two clusters suggested from findings.

Table 3: Scale for Type of Cluster for Male

\begin{tabular}{clll}
\hline \multirow{2}{*}{ Cluster } & & \multicolumn{1}{c}{ Scale } & High \\
\hline 1 & & Moderate & Independent, Avoidant, Dependent, Participant \\
2 & Independent & Avoidant, Collaborative, Dependent, Competitive, Participant & Collaborative, Competitive \\
\hline
\end{tabular}

Based on Table 3 above, learning style for cluster 1 are highly in competitive and collaborative styles while independent, avoidant, dependent and participant styles are in moderate. Learning styles for cluster 2 are moderate in participant, dependent, avoidant, collaborative and competitive styles while low in independent style. Based on cluster for male, learning style for cluster 1 are competitive and collaborative styles. Learning styles for cluster 2 lack in independent style. 


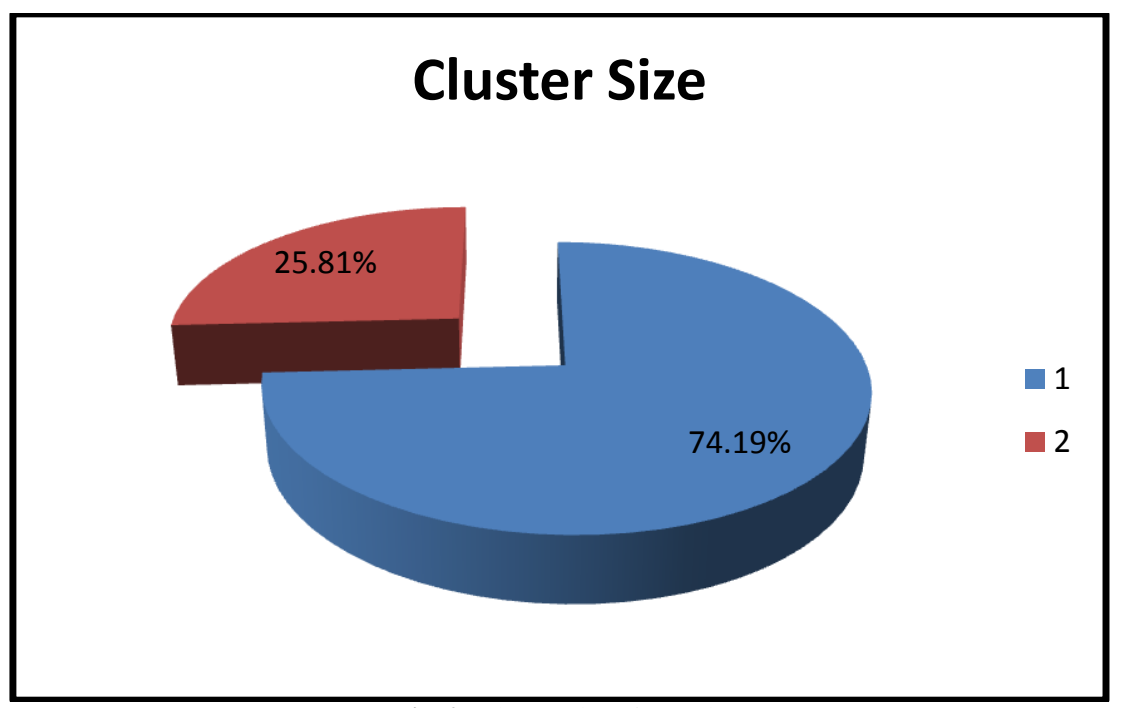

Fig. 2: Cluster Sizes for Male

Figure 2 shows the frequency of each cluster. Hovering over a slice in the pie chart reveals the number of records assigned to the cluster. $74.19 \%$ (23) of the records were assigned to the first cluster and $25.81 \%$ (8) to the second cluster. One can be conclude that the male group is prone to indicate as a Cluster 1 whereby address on collaborative and competetive. Thus, it can be sure that both learning style should be outlined for teachers or lecturers to improve these skills. On the contary of female group is presented four cluster provided through cluster analysis.

\begin{tabular}{clll}
\multicolumn{2}{c}{ Table 4: Scale for Type of Cluster of Female } & \multicolumn{1}{c}{ Scale } & High \\
\hline \multirow{2}{*}{ Cluster } & Low & Moderate & $\begin{array}{l}\text { Collaborative, } \\
\text { Competitive }\end{array}$ \\
\hline 1 & & Independent, Avoidant, Dependent, Participant & \\
& & Independent, Avoidant, Dependent, Participant, Collaborative, & \\
3 & & Competitive & Competitive \\
4 & Independent & Dependent, Participant, Avoidant & Collaborative, \\
Competitive
\end{tabular}

Based on Table 4 above, learning style for cluster 1 are highly in collaborative and competitive styles while independent, avoidant, dependent and participant styles are in moderate. Learning styles for cluster 2 are moderate in independent, avoidant, dependent, participant, collaborative and competitive styles. Learning styles for cluster 3 are highly in competitive while moderate in independent, avoidant, dependent, participant and collaborative style. Lastly, learning styles for cluster 4 are highly in collaborative and competitive style, moderate in dependent, participant and avoidant and low in independent styles. Based on cluster for female, learning style for cluster 1 are collaborative and competitive styles. Learning styles for cluster 2 is non-style includes. Learning styles for cluster 3 are competitive. Lastly, learning styles for cluster 4 are collaborative and competitive style but lack in independent styles.

\section{Cluster Size}

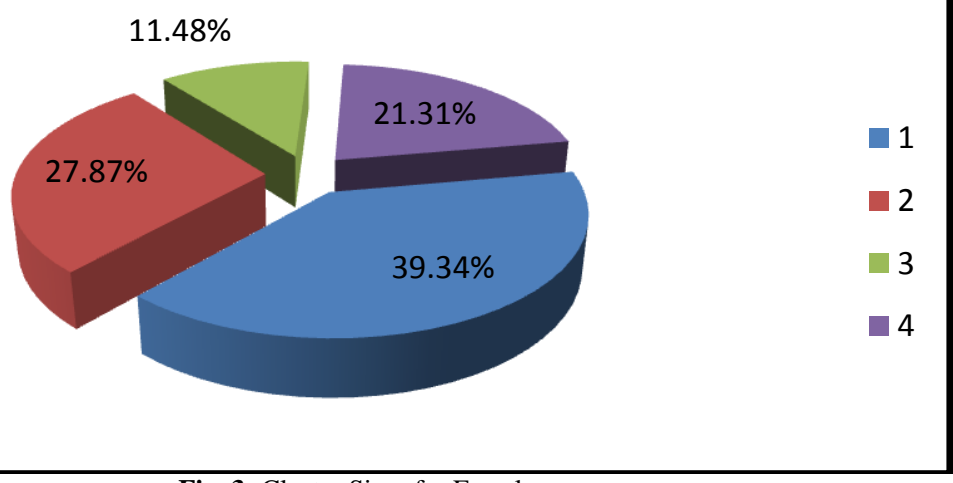

Fig. 3: Cluster Sizes for Female 
Figure 7.1 shows the frequency of each cluster. Hovering over a slice in the pie chart reveals the number of records assigned to the cluster. $39.34 \%$ (48) of the records were assigned to the first cluster, $27.87 \%$ (34) to the second cluster, $11.48 \%$ (14) to the third and $21.31 \%$ (26) to the fourth cluster. In the instance, the female group interest towards cluster 1 whereby collaborative and competitive.

Table 5: ANOVA Table for Mathematics Achievements

\begin{tabular}{llllll}
\hline & Sum of Squares & Df & Mean Square & F & Sig. \\
\hline Between Groups & 0.949 & 3 & 0.316 & 0.455 & 0.714 \\
Within Groups & 103.730 & 149 & 0.696 & & \\
Total & 104.680 & 152 & & & \\
\hline
\end{tabular}

Table 5 shown that, the value is not significant since 0.714 is more than 0.05 . So, there is no significant difference between learning style towards mathematic achievements. Specifically, as the statistician, we deserved to accept the null hypothesis to indicate the difference between learning style and mathematic achievement. Yet, some researchers may identify the substantive hypothesis accordance of F-test with the help of statistical table but it depends on interest of researchers and scholars. In this instance, this paper often makes an interpretation based on significant values whereby appear in output of SPSS. For the information, all of the analysis provided should be coincide of our objective research. As we can see the Table 8 presented, ANOVA table is chosen to determine the significant difference of learning style and mathematics achievement since the groups is contain of more than two groups.

\section{Conclusions}

Based on the objectives of this study, the clusters of learning styles have been identified as four groups. Male and female have differed type of learning styles. By inspecting through the finding, there are two clusters for male while four clusters for female. There is no significant difference between learning style towards mathematics achievements. The difference of learning style between students doesn't give an impact on mathematic achievements. There could be other possible predictor of academic performance. It may be attributable to the types of students as off-campus or oncampus students, whether or not they were university students, number of previous courses taken in the subject area, limited or unlimited computer access, study and work hours per week, and gender-were not associated with their webbased learning achievement. [3].

Table 6: Summary for Type of the Learning Style

\begin{tabular}{ll}
\hline Group & Type of the learning style \\
\hline cluster 1 & collaborative/competitive \\
cluster 2 & collaborative/participant/dependent \\
cluster 3 & competitive \\
cluster 4 & collaborative \\
\hline
\end{tabular}

Table 7: Summary for Type of the Learning Style between Genders

\begin{tabular}{lll}
\multicolumn{2}{c}{ Table 7: Summary for Type of the Learning Style between Genders } \\
\hline Group & Type of the learning style (male) & Type of the learning style (female) \\
\hline cluster 1 & collaborative/competitive & collaborative/competitive \\
cluster 2 & lack independent & non-style are includes \\
cluster 3 & & competitive \\
cluster 4 & & collaborative/competitive but lack independent \\
\hline
\end{tabular}

\section{Recommendation}

University administrators should plan activities for learning and education for students that fit their learning styles or give them hints about how to learn using their preferred learning styles to increase mathematic achievement. Therefore, work to identify these styles when students seem to have difficulties in learning and providing them with suggestions on how to overcome the struggles. In the future research, this study should be added more variables to improve the impact of contribution of the case study besides rely on the distinct of style provided. In order to give an impact interest for the readers outside, the probing studies should be better with existing of the graphic modeling for cluster analysis since this application provided is too tedious. Thus, these authors recommend applying Respond Based Segmentation Partial Least Square Structural Equation Modeling (REBUS-PLS) for the next research paper aside to keep the substantive theory. On the use of suggested model possible is tend to illuminate the reasons of particular of case study in while avoid an ambiguity of an explanation in the case study. Precisely, the readers will be better understanding to capture the capabilities of particular application. 


\section{Acknowledgements}

Thanks to all that participated in this study.

\section{References}

[1] Andrews RH. (1990). the development of a learning styles program in a low socioeconomic, underachieving North Carolina elementary school. J. Reading Writing Learn. Disabil. Int., 6: 307-314.

[2] Cano J. (1999). The relationship between learning style, academic major, and academic performance of college students. J Agric. Educ., 40: 30-37.

[3] Ching, T. Y., Dillon, H., Day, J., Crowe, K., Close, L., Chisholm, K., \& Hopkins, T. (2009). Early language outcomes of children with cochlear implants: Interim findings of the NAL study on longitudinal outcomes of children. Cochlear implants international, 10(Supplement1), 28-32

[4] Coffield, F., Moseley, D., Hall, E., \& Ecclestone, K. (2004). Learning styles and pedagogy in post-16 learning: A systematic and critical review. Retrieved July 01, 2012 from http://www.lsda.org.uk/files/PDF/1543.pdf

[5] Diaz DP \& Cartnal RB. (1999). Students 'learning styles in two classes: Online distance learning and equivalent on-campus. Coll. Teach., 47(4): 130-135.

[6] Dunn R, Griggs SA, Gorman B \& Beasley M. (1995). A meta-analytic validation of the Dunn and Dunn model of learning-style preferences. J. Educ. Res., 88: 353-361.

[7] Grasha, A. F. (1994). A matter of style: The teacher as expert, formal authority, personal model, facilitator, and delegator. College teaching, 42(4), 142-149.

[8] Grasha, A.F., (1996). Teaching with style: A practical guide to enhancing learning by understanding teaching and learning styles. San Bernardino, CA: Alliance Publishers.

[9] Grasha-Riechmann Student Learning Style Scale. (2012). Retrieved May 30, 2012, from http://www.ehow.com/about_5511314_grashariechmann-student-learning-style-scale.html Honey P \& Mumford A. (1992). The Manual of Learning Styles 3rd Ed. Maidenhead, Peter Honey.

[10] Klavas A. (1994). Learning style program boosts achievement and test scores. The Clearing House, 67: 149-151.

[11] Porter T \& Cano J. (1996). Relationship between learning styles, academic major, and academic performance of Ohio State freshmen in College of Food, Agricultural, and Environmental Sciences. Paper presented at the annual Council of Graduate StudentsResearch Forum, The Ohio State University, and Columbus.

[12] Prabhakar V \& Swapna B. (2009). Influence of learning styles. Int. J Learn, 16(9).

[13] Rasimah A \& Zurina M. (2008). Student's Learning Styles and Academic Performance. Annual SAS Malaysia Forum, July 2008, Kuala Lumpur Convention Center.

[14] Rayneri LJ \& Gerber BL. (2004). Student perception inventory. Roeper Rev., 26: 90-95.

[15] Rayneri, L. J., \& Gerber, B. L. (2004). Development of a student perception inventory. Roeper Review, 26(2), 90-95.

[16] Riechmann, S. W., \& Grasha, A. F. (1974). A rational approach to developing and asessing the construct validity of a student learning styles instrument. Journal of Psychology, 87, 213223.

[17] Sorrell, M. F., Belongia, E. A., Costa, J., Gareen, I. F., Grem, J. L., Inadomi, J. M.,\& Trotter, H. T. (2009). National Institutes of Health consensus development conference statement: management of hepatitis B. Hepatology, 49(S5), S4-S12. 